Ultrasonic characterization of pork meat salting

This article has been downloaded from IOPscience. Please scroll down to see the full text article.

2012 IOP Conf. Ser.: Mater. Sci. Eng. 42012043

(http://iopscience.iop.org/1757-899X/42/1/012043)

View the table of contents for this issue, or go to the journal homepage for more

Download details:

IP Address: 158.42.80.248

The article was downloaded on 17/12/2012 at 10:51

Please note that terms and conditions apply. 


\title{
Ultrasonic characterization of pork meat salting
}

\author{
J V García-Pérez, M De Prados, N Pérez-Muelas, J A Cárcel and J Benedito ${ }^{1}$ \\ Grupo de Análisis y Simulación de Procesos Alimentarios (ASPA), Departamento de \\ Tecnología de los Alimentos, Universitat Politècnica de València, 46022, Valencia, \\ Spain \\ E-mail: jjbenedi@tal.upv.es
}

\begin{abstract}
Salting process plays a key role in the preservation and quality of dry-cured meat products. Therefore, an adequate monitoring of salt content during salting is necessary to reach high quality products. Thus, the main objective of this work was to test the ability of low intensity ultrasound to monitor the salting process of pork meat. Cylindrical samples (diameter $36 \mathrm{~mm}$, height $60 \pm 10 \mathrm{~mm}$ ) of Biceps femoris were salted (brine $20 \% \mathrm{NaCl}, \mathrm{w} / \mathrm{w}$ ) at $2{ }^{\circ} \mathrm{C}$ for 1 , 2, 4 and 7 days. During salting and at each experimental time, three cylinders were taken in order to measure the ultrasonic velocity at $2{ }^{\circ} \mathrm{C}$. Afterwards, the cylinders were split in three sections (height $20 \mathrm{~mm}$ ), measuring again the ultrasonic velocity and determining the salt and the moisture content by AOAC standards. In the whole cylinders, moisture content was reduced from 763 (g/kg sample) in fresh samples to $723(\mathrm{~g} / \mathrm{kg}$ sample) in samples salted for 7 days, while the maximum salt gain was 37.3 ( $\mathrm{g} / \mathrm{kg}$ sample). Although, moisture and salt contents up to 673 and 118 ( $\mathrm{g} / \mathrm{kg}$ sample) were reached in the sections of meat cylinders, respectively. During salting, the ultrasonic velocity increased due to salt gain and water loss. Thus, significant $(\mathrm{p}<0.05)$ linear relationships were found between the ultrasonic velocity and the salt $\left(R^{2}=0.975\right)$ and moisture $\left(R^{2}=0.863\right)$ contents. In addition, the change of the ultrasonic velocity with the increase of the salt content showed a good agreement with the Kinsler equation. Therefore, low intensity ultrasound emerges as a potential technique to monitor, in a non destructive way, the meat salting processes carried out in the food industry.
\end{abstract}

\section{Introduction}

Salting is one of the most ancients preservation methods used in food stuffs [1] because of the fact that salt is a multifunctional ingredient that affects both quality and safety. One of the main salted products is the dry-cured meat. Dry-cured ham is one of the most valuable in Spanish meat market [2]. During salting, salt content increases (by 3-5\%) and water content decreases (by $9 \%$ ) and the product loses weight [3]. There is a great variability in the final salt content due to among other factors, the different structure and composition of raw meat. Moreover, there is also a higher consumer's demand of drycured products with low salt content due to changes in sensory preferences and the increase public concern as regards the high intake of sodium in the diet [4]. These facts lead to the industry to seek for an adequate monitoring of salting process, especially in a non-destructive way.

The number of applications of low intensity ultrasound in the food industry has mostly increased during the last decade [5]. The main reason for this increase arises from the fact that ultrasonic technologies are non-destructive, rapid, low-cost and easy to be automated on-line [6]. Ultrasonic has

1 To whom any correspondence should be addressed. 
been used to determine the physicochemical properties of many foods [7]. In the meat industry, ultrasound has been used to determine the carcass yields of Iberian pigs, the intramuscular fat content in meat and carcasses [8] and to estimate the moisture content of dry-cured meat products [9]. Furthermore, ultrasonic velocity has been also used to assess the quality of fresh back-fat from Iberian pigs [10]. Thus, the main objective of this work is to test the ability of low intensity ultrasound to monitor the salting process of pork meat.

\section{Materials and methods}

\subsection{Sample Preparation}

Salting experiments were carried out using 12 meat cylinders of $36 \mathrm{~mm}$ in diameter and $60 \pm 10 \mathrm{~mm}$ in length obtained from Biceps Femoris of white pork. Meat cylinders were placed in a copper cylinder in order to avoid the mass transfer through radial direction. Only one side of the cylinder was immersed in the brine solution, while the other side was covered by plastic film to avoid air drying. Thus, from a theoretical point of view, it could be considered that meat cylinders behave as infinite slabs $(\mathrm{L}=60 \pm 10 \mathrm{~mm})$ and the mass transfer is simplified as one-dimensional. Salting was carried out using a brine solution of $20 \%(\mathrm{NaCl}, \mathrm{w} / \mathrm{w})$ and temperature was hold at $2{ }^{\circ} \mathrm{C}$. Three cylinders were removed from the brine at different times (24, 48, 96 and 168 hours) and the ultrasonic velocity was measured in the whole cylinder. Afterwards, the cylinders were sliced in 3 parts of $20 \pm 3 \mathrm{~mm}$ thickness, being measured the ultrasonic velocity and the salt and moisture content in each section.

\subsection{Ultrasonic velocity measurements}

Figure 1 shows the experimental set-up used in this work, it mainly consisted of a couple of narrowband ultrasonic transducers $(5 \mathrm{MHz}, 0.75$ " diameter, V308 model, Panametrics NAT, Walthman, MA, USA), a pulser-receiver (Panametrics, Model 5058PR, Waltham, USA) and a digital oscilloscope (Tektronix, TDS5034, Digital phosphor oscilloscope. Tektronix inc. Bearverton, Oregon. USA). A custom digital height gage was designed and built, and linked to the computer by a RS232 interface to measure the sample thickness. The ultrasonic velocity in the sample was computed from the time of flight [11] and the thickness provided by the height gage. The ultrasonic velocity was determined for all samples (the whole cylinders and their three sections) at $2^{\circ} \mathrm{C}$ in a temperature-controlled chamber.

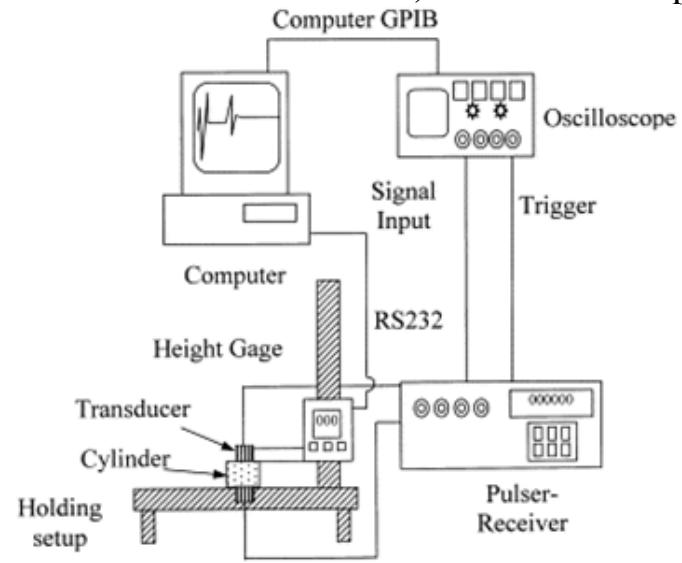

Figure 1. Ultrasonic set-up for velocity measurements.

\subsection{Chemical composition}

Salt and moisture content were measured according to AOAC standards (AOAC, 1997). In all cases, the measurement was carried out, at least, in triplicate.

\section{Results and discussion}




\subsection{Influence of salting time on composition and ultrasonic velocity}

Figure 2 shows the evolution of moisture and salt content during salting in the whole cylinders. As can be observed, samples lost water and gained salt during salting. The average water content decreased from $763 \pm 37$ to $723 \pm 78$ (g/kg sample). While the salt content increased from $1.0 \pm 0.3$ to $37.1 \pm 8.2$ (g/kg sample). In the sections of meat cylinders, moisture and salt contents up to 673 (g/kg sample) and $118(\mathrm{~g} / \mathrm{kg}$ sample) were reached, respectively

The influence of salting time on the ultrasonic velocity is shown in figure 3 . The ultrasonic velocity increased during salting. This increase is ascribed to two superimposed effects, the decrease of moisture and the gain of salt, which increase the solid content in the liquid phase. Similar results have been obtained for the ripening of several types of cheese, where the ultrasonic velocity increases due to the decrease of water content and the increase of solids [12].

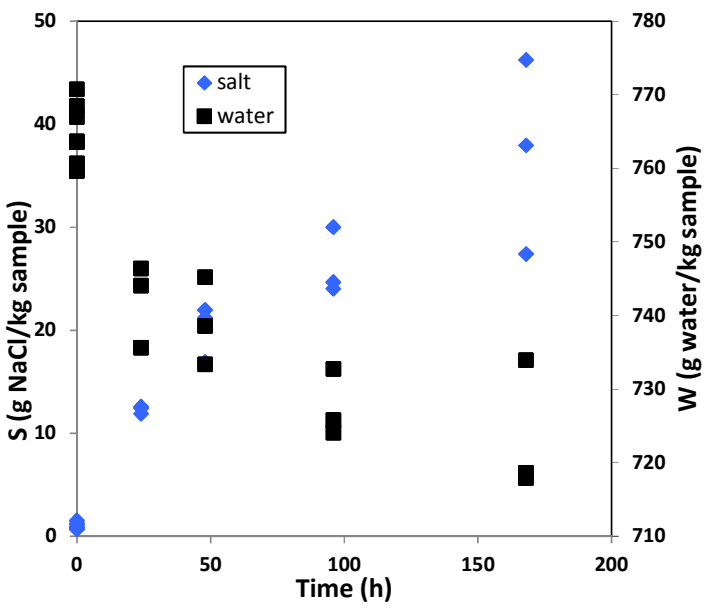

Figure 2. Evolution of moisture and salt content of whole cylinders $(37 \mathrm{~mm}$ in diameter y $60 \pm 10 \mathrm{~mm}$ in length) of Biceps Femoris (BF) during salting $2{ }^{\circ} \mathrm{C}$.

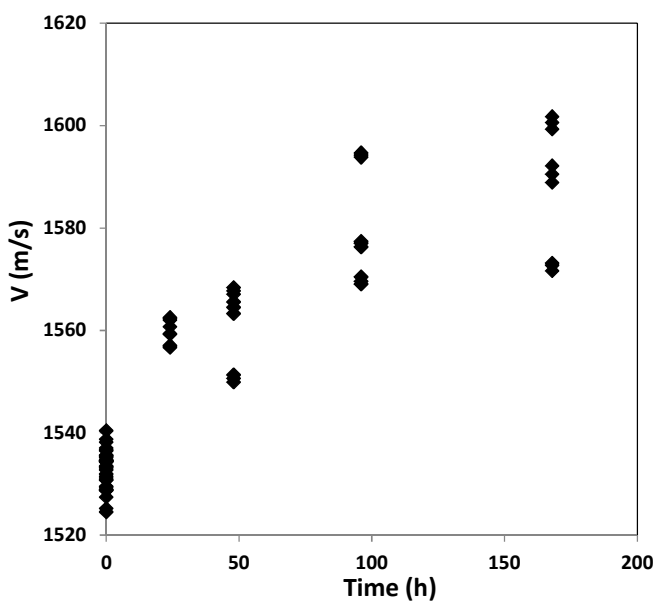

Figure 3. Evolution of ultrasonic velocity in whole cylinders $(37 \mathrm{~mm}$ in diameter y $60 \pm 10$ $\mathrm{mm}$ in length) of Biceps Femoris (BF) during salting $2^{\circ} \mathrm{C}$.

\subsection{Influence of salt and moisture content on the ultrasonic velocity}

Figure 4 and 5 show, for the cylinder's sections, the influence of salt and moisture content on the ultrasonic velocity. The ultrasonic velocity increased with the reduction of moisture content and the gain of salt, being established significant $(\mathrm{p}<0.05)$ lineal relationships in both cases. The slope of the linear relationship determines how the ultrasonic velocity changes due to the change of moisture or salt. Thus, in the case of salt, the slope indicates that the ultrasonic velocity increases $1.46 \mathrm{~m} / \mathrm{s}$ per $\mathrm{g} / \mathrm{kg}$ of salt gain, while in the moisture content, the slope means that the ultrasonic velocity decreases $1.62 \mathrm{~m} / \mathrm{s}$ per $\mathrm{g} / \mathrm{kg}$ of water lost. During salting, salt and moisture transfer are superimposed effects, thus, further works will be addressed to separate and correctly discriminate the influence of moisture and salt on ultrasonic velocity. Figure 5 also shows the experimental equation of Kinsler (equation (1)), which represents the influence of salt content on the ultrasonic velocity in a water solution [13]. It is observed in figure 5 that, regardless the different structure of meat and water solution, the slope of both linear relationships are similar. The results obtained in this work show that the ultrasound velocity measurements could be used to monitor the pork meat salting for quality control purposes.

$$
V=1449+4.6 T-0.055 T^{2}+0.0003 T^{3}+(1.39-0.012 T)(C-35)
$$

Where $V$ is velocity $(\mathrm{m} / \mathrm{s}), T$ is temperature $\left({ }^{\circ} \mathrm{C}\right)$ and $C$ is the salt concentration $(\mathrm{g} / \mathrm{kg})$. 


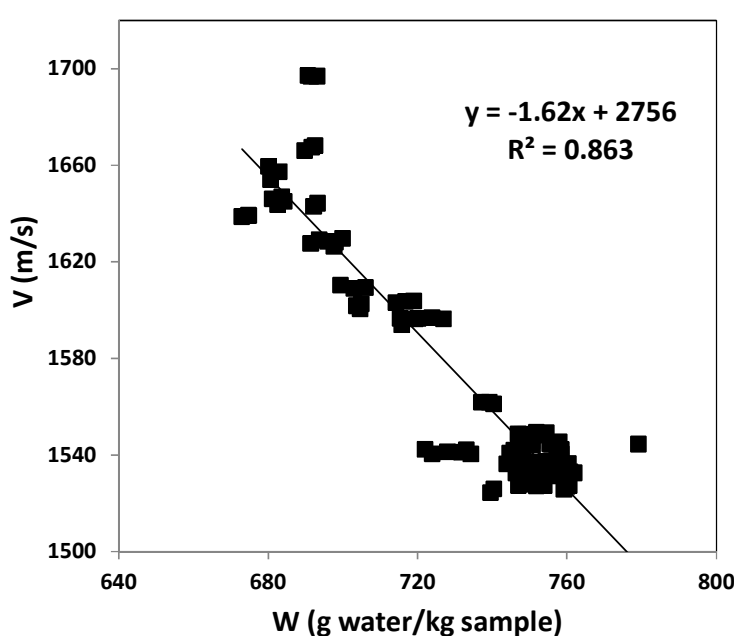

Figure 4. Relationship between ultrasonic velocity and the moisture content of Biceps Femoris (BF) cylindrical sections.

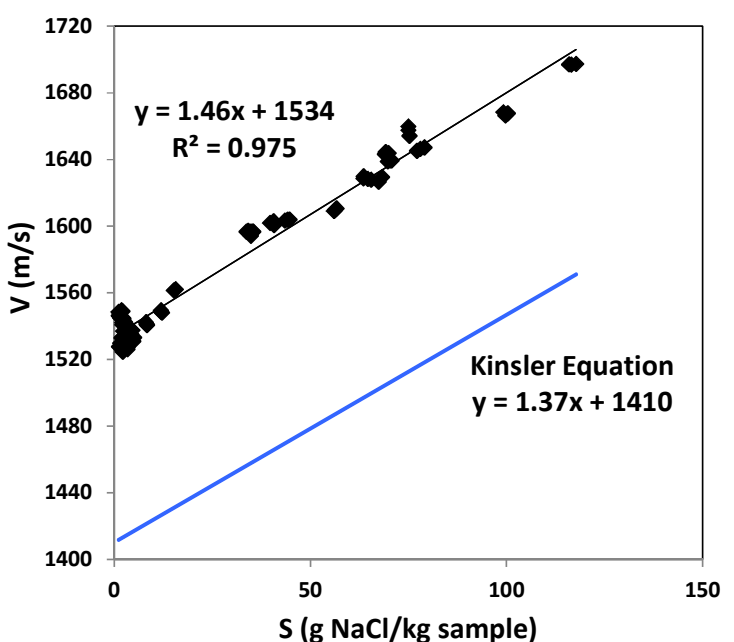

Figure 5. Relationship between ultrasonic velocity and the salt content of Biceps Femoris (BF) for cylindrical sections and Kinsler equation.

\section{Conclusion}

The ultrasonic velocity increased in the samples during salting due to the gain of salt and the loss of water. Moreover, significant linear relationships were established between the salt and moisture content and the ultrasonic velocity. According to these results, the application of ultrasound to monitor the change of salt and moisture during salting could be of great interest for industrial purposes.

\section{Acknowledgements}

The authors acknowledge financial support from the "Ministerio de Economía y Competitividad" in Spain (Project RTA 2010-00029-C04-02).

\section{References}

[1] Binkerd E F and Kolari O E 1975 Food and Cosmetics Toxicology 13 655-661

[2] Gou P, Comaposada J and Arnau J 2002 Meat Science 61 (1) 25-31

[3] Bello J 2008 Jamón Curado Aspectos Científicos y Tecnológicos. Perspectivas desde la Unión Europea (Spain: Diaz de Santos) pp 206-216

[4] World Health Organization/Food and Agriculture Organization 2003 Diet, Nutrition and the Prevention of Chronic Disease Technical Report Series 916 (Geneva: World Health Organization)

[5] Benedito J, Carcel J A, Gonzalez R and Mulet A 2002 Ultrasonics 40 19-23

[6] D J McClements 1997 Critical Reviews Food Science Nutrition 371

[7] Coupland J N 2004 Food Research International 37 537-543

[8] Mörlein D, Rosner F, Brand S, Jenderka K-V and Wiche M 2005 Meat Science 69 187-199

[9] Llul P, Simal S, Femenia A, Benedito J and Rosello C 2002 J. Food Eng. 52 323-330

[10] Niñoles L 2007 Contribución a la Caracterización de la Calidad de Productos del Cerdo mediante Ultrasonidos de Señal Doctoral Thesis (Valencia: UPV)

[11] Benedito J, Carcel J, Roselló C and Mulet A 2001 Meat Science 57 365-370

[12] Benedito J J 1998 Contribución a la Caracterización de Quesos mediante el Uso de Ultrasonidos de Señal Doctoral Thesis (Valencia: UPV)

[13] Kinsler L E, Frey A R, Coppens A B and Sanders J V 1982 Fundamentals of Acoustics (New York: John Wiley and Sons) 